\title{
A RARE CASE OF NEUROFIBROMATOSIS WITH SQUAMOUS CELL CARCINOMA OF EPIGLOTTIS
}

Authors: (1) Jayendiran S, (2) Harish VelV (3) Srinivasa V (4) Swetha Lakshmi M

Authors Affiliations: (1) Senior resident , $(2,4)$ Post graduate (3) Professor,Head Department of Otorhinolaryngology,Vinayaka Mission's Medical College \&Hospital, Karaikal, Puducherry 609609

\section{*Corresponding Author:}

Dr.Harish VelV

Postgraduate , Department of Otorhinolaryngology ,Vinayaka Mission's Medical College \&Hospital, Karaikal, Puducherry-609609. PHONE NUMBER: 9750188393

EMAIL:harishvel1807@gmail.com

ORCIDID:0000-0001-7334-1867

\section{ABSTRACT}

INTRODUCTION: The neurofibroma is a nonmalignant new growth of neuroectodermal origin. neurofibromas appear at the end of a nerve, often in the skin, producing small nonencapsulated nodules which may have pigmentation in the overlying skin. Neurofibromatosis with laryngeal involvement presents with dyspnea, followed by hoarseness, stridor, dysphagia, and voice change. most common sites involved in the larynx are the arytenoids and the aryepiglottic folds.

\section{CASE REPORT:}

65-year-old female with previously diagnosed of neurofibromatosis since 10 years of age manifested by multiple cutaneous nodules The patient had symptoms of dysphagia, hoarseness of voice for past 2 months. Direct laryngeal examination using flexible endoscope showed a edematousulceroproliferative growth in the laryngeal surface of epiglottis and fullness in the left pyriform fossa. Hisopathological examination revealed squamous cell carcinoma from epiglottis and fibromatosis changes from pyriform fossa.

CONCLUSION: All neurofibromatosis patient and their family members should under go regular oral and laryngeal examination to rule out complications at the earliest.

\section{INTRODUCTION}

Neurofibromatosis in larynx are extremely rare, especially in the subglottic part. Characteristic symptoms of laryngeal tumors include hoarseness, dysphagia, odynophagia, dysarthria, a globus sensation, dyspnea and shortness of breath ${ }^{1}$.Majority of tumors arising in NF1 patients are neurofibromas, particularly plexiform neurofibromas. Malignant peripheral nerve sheath tumors also affect these patients. Furthermore, patients with NF1 have a greatly increased risk of developing gliomas, leukemia, particularly juvenile myelomonocytic leukemia, pheochromocytoma and rhabdomyosarcoma ${ }^{2,3}$. In addition, certain types of carcinomas, including breast cancer, may also occur more frequently in patients with NF1 ${ }^{2,4,5}$.Occurrence of cutaneous squamous cell carcinoma (SCC) in patients with NF1 has been rarely documented ${ }^{6}$.The present study describes a case of laryngeal squamous cellcarcinoma(SCC).

\section{CASE REPORT}

A 65-year-old female with previously diagnosed of neurofibromatosis since 10 years of age manifested by multiple cutaneous nodules The patient had symptoms of dysphagia, hoarseness of voicefor past 2 months. She is a known case of pulmonary tuberculosis 20 years ago for which she took full treatment course. No history of any addiction. Her physical examination was remarkable formultiple cafe au lait spots and subcutaneous nodules.FIG 1.0 She also has a family history of neurofibromatosis in her mother and her sister and her son.Indirectlaryngoscopic examination demonstrated a enlarged epiglottis with lesions on its laryngeal surface with left pyriform fossa fullness. Direct laryngeal examination using flexible endoscpe showed a edematousulceroproliferative growth in the laryngeal surface of epiglottis and fullness in the left pyriform fossa. Fig, 1.1, 1.2,1.3

FIG 1.4 Xray of neck soft tissue lateral view 
To confirm diagnosis patient was posted for laryngeal biopsy under general anaesthesia.Multiple biopsy from epiglottis and left pyriform fossa was taken and sent for histopathological examination.Thehisopathological examination revealed squamous cell carcinoma from epiglottis and fibromatosis changes from pyriform fossa

FIG 1.5,1.6

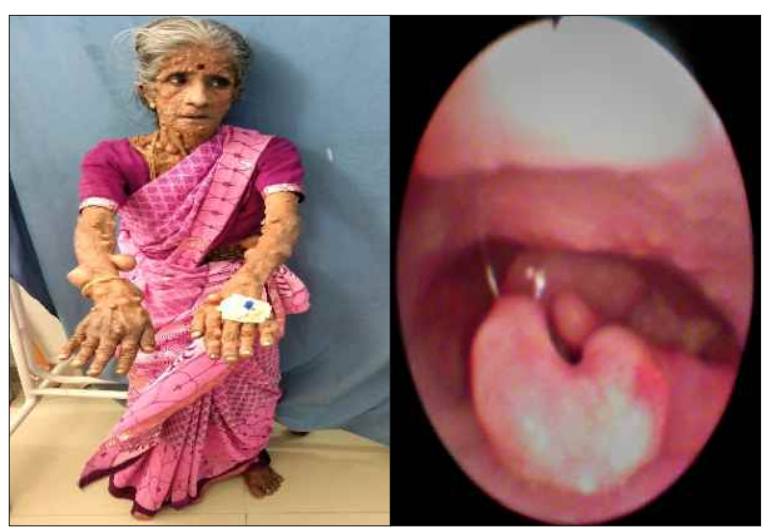

FIG: 1.0 NEUROFIBROMATOSIS PATIENTFIG

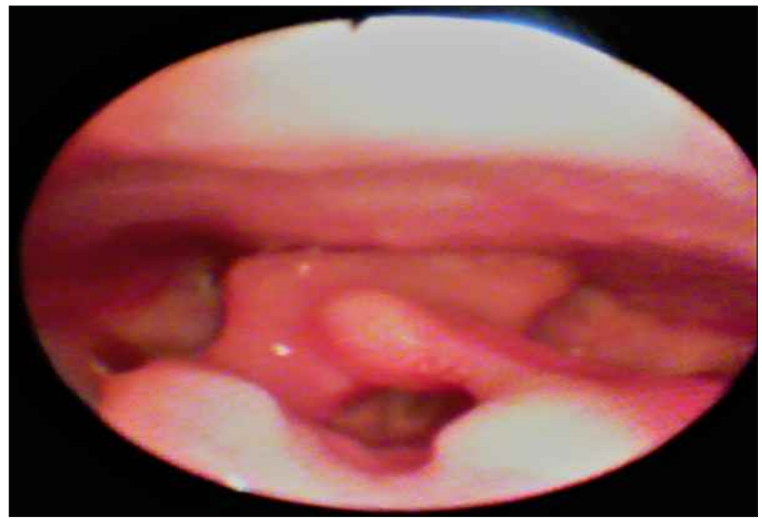

:1.1VIDEOLARYNGOSCOPY

FIG:1.3 Fullness in the Left Pyriform Fossa

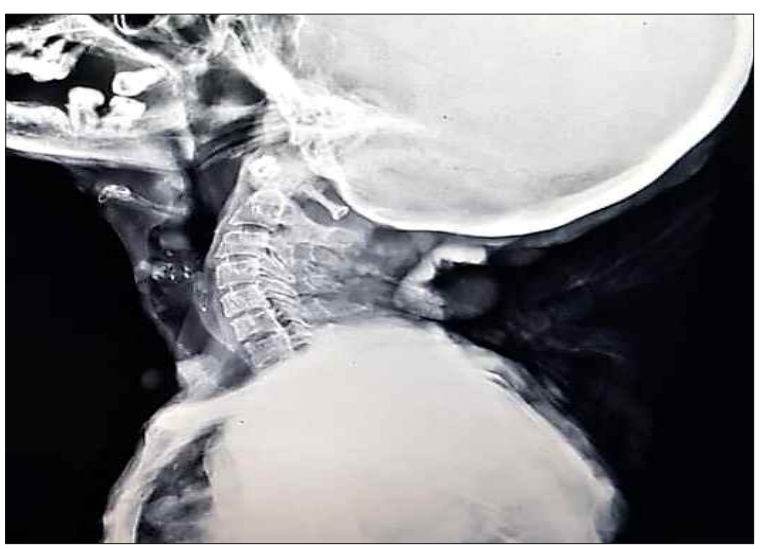

FIG 1.4 Xray of neck soft tissue lateral FIG 1.5 Hisopathological examination revealed

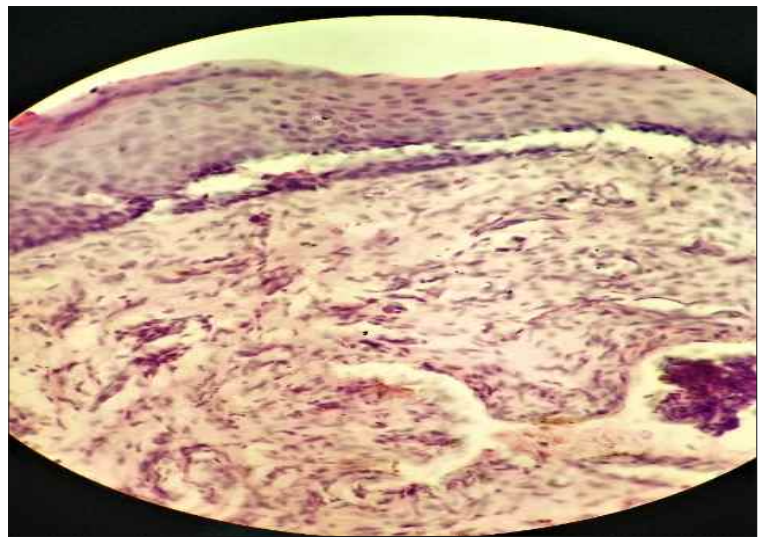

squamous cell carcinoma from epiglottis and fibromatosis changes from pyriform fossa FIG 1.6 Hisopathological examination revealed

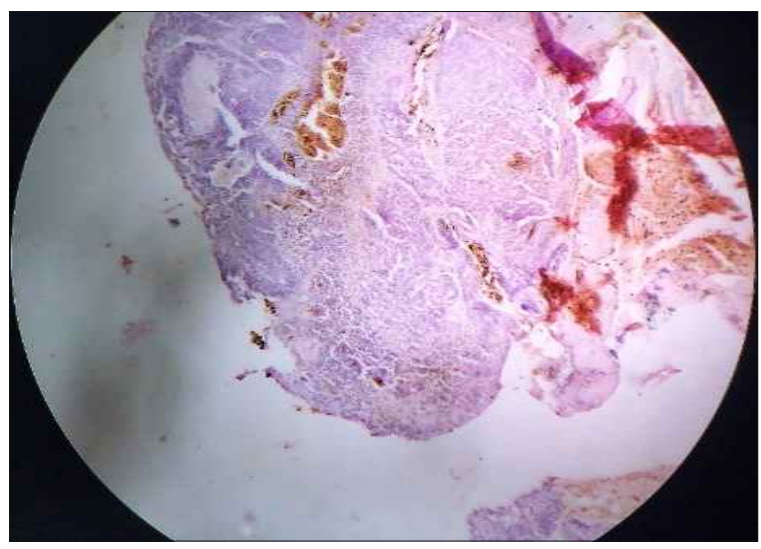

squamous cell carcinoma from epiglottis and fibromatosis changes from pyriform fossa

\section{DISCUSSION}

Neurofibromatosis (NF) is an autosomal dominant disorder mainly characterized by abnormalities in the skin and nervous system. Neurofibromatosis are of 8 subtypes but NF1 and NF2 are the best described variants. NF1 is also known as peripheral NF.

National Institutes of Health diagnostic criteria for neurofibromatosis type 1

- Six or more cafe-au-lait macules (>5 mm diameter in children, $>15 \mathrm{~mm}$ in adults)

- Two or more cutaneous or subcutaneous neurofibromas or one plexiform neurofibroma

-Axillary or inguinal freckling

- Optic-pathway glioma

-Two or more Lisch nodules

- Bone dysplasia

-First-degree relative with neurofibromatosis type 1

NF2 is known as central NF and is generally 
characterized by bilateral vestibular schwannomas presenting with hearing loss during the second or third decades()

Most common sites of laryngeal involvement include the aryepiglottic folds and the arytenoids, areas of the larynx rich in terminal nerve plexuses. It has been postulated that this location implies a tumor origin from the superior laryngeal nerve andfrom anastomoses between the superior laryngeal nerve and the recurrent laryngeal nerve. ${ }^{7-9}$

In 1849, Robert W. Smithfirst published a review of the disease and suggested that the originof the tumors was the connective tissue surrounding small nerves10. In 1882, Friedrich von Recklinghausen recognized that the tumors included both neural and fibrous tissue derived from peripheral nerves 11

A review article by Chang Lo in 1977 reported 20 cases of laryngeal involvement with neurofibromatosis. The most commonpresenting symptom is dyspnea, followed by hoarseness, stridor, dysphagia, and voice change. Half of the casesmanifest in childhood and half in young adulthood.

This patient has generalized neurofibromatosis (von Recklinghausen's disease) for many years. Hoarseness and increasing dyspnea brought him to laryngeal examination. Histological examination revealed squamous cell carcinoma. Combined neurofibroma and squamous-cell carcinoma in the larynx has been reported rarely. This case is considered worthy of documentation

\section{Conclusion:}

The neurofibromatosis patient should under go regular oral and laryngeal examination and the family members of such patients also should under go regular check up to rule out complications at the earliest

\section{REFERENCES}

1. Gstöttner, M., Galvan, O., Gschwendtner, A. and Neher, A., 2005. Solitary subglottic neurofibroma: a report of an unusual manifestation. European Archives of OtoRhino-Laryngology and Head \& Neck, 262(9), pp.705-707.

2. Seminog $\mathrm{OO}$ and Goldacre MJ: Risk of benign tumours of nervous system, and of malignant neoplasms, in people with neurofibromatosis: population-based record-linkage study. Br J Cancer 108: 193198, 2013.

3. Zöller ME, Rembeck B, Odén A, Samuelsson $M$ and Angervall $L:$ Malignant and benign tumors in patients with neurofibromatosis type 1 in a defined Swedish population. Cancer 79: 2125-2131, 1997. Breast cancer associated with type 1 neurofibromatosis. Breast Cancer 17:306-309, 2010.

4. Sharif S, Moran A, Houson SM, et al: Women with neurofibromatosis 1 are at a moderately increased risk of developing breast cancer and should be considered for early screening. J Med Genet 44: 481-484, 2007

5. Friedrich RE, Al-Dam $A$ and Hagel C: Squamous cell carcinoma of the sole of the foot in neurofibromatosis type 1 . Anticancer Res 32:2165-2168, 2012.

6. Smith TT (1944) Solitary neurofibroma of the larynx. Arch Otolaryngol 39:14-15114:161-170

7. Hirsch NP, Murphy A, Radcliffe JJ. Neurofibromatosis: clinical presentations and anesthetic implications. $\mathrm{Br} J$ Anaesth. 2001;86:555-564.

8. Czinger J, Fekete-szabo G. Neurofibroma of the supraglottic larynx in childhoodJLaryngol Otol. 1994;108:156-158

9. Willcox TO, Rosenberg SI, Handler SD. Laryngeal involvement in neurofibromatosis. Ear Nose Throat J. 1993;72:811-812

10. Smith RW. A Treatise on the Pathology, Diagnosis and Treatment of Neurofibroma.Dublin, Ireland: Hodges \& Smith; 1849.

11. Von Recklinghausen FD. Uber die multiplenFibromeder Haut und ihreBeziehungzudenmultiplenNeuromen. Berlin, Germany: A Hirschwald; 1882.

12. Fukuda I, Ogasawara H, Kumoi, Sugihara K, Wada $\mathrm{H}$ (1987) Subglottic neurofibroma in a child. Int J PediatrOtorhinolaryngol 